\title{
Possibilities of Regional Trade Expansion: A Link Model for Pakistan, India, Bangladesh and Sri Lanka
}

\author{
SYEd NAWAB HAIDER NAQVI, ATHER MAQSOOD AHMED and \\ ASHFAQUE H. KHAN*
}

Econometric models are generally constructed for a specific country on the assumption that national economies are independent. In reality, this is not the case. In this paper, we have constructed prototype linkage econometric models for Pakistan, India, Bangladesh and Sri Lanka. These models are linked to each other through foreign-trade equations to explore possibilities of fruitful economic cooperation among these four countries Policy simulations, carried out to highlight the pay-off of specific policies in terms of the stated objective, show that, given the resolve of these countries to extend the area of collaboration, the prospects are by no means dim. There is also the extra bonus that the growth of GNP in the region will also be helped by mutual economic co-operation. The need for conscious policy decisions to this effect has been underscored.

\section{INTRODUCTION}

Rapid progress has been made in the art of econometric modelling in both developed and developing countries ever since Tinbergen and Klein made their pioneering contribution in this highly fertile area of research. Econometric models are generally constructed for specific countries, without an explicit linkage with other countries, and assume that policy measures taken in one country do not affect other countries or regions. In reality, national economies are linked through foreign trade, capital movements and migration. It was this realization that led to the creation of the Project LINK in 1968, with the express purpose of tying together national models to provide a consistent framework for studying the phenomenon of interdependence of national economies. Similar efforts are now being pursued by the ESCAP Secretariat through the Project Asian Sub-Link to promote a better understanding of the extent of interdependence among the economies of the region. ${ }^{1}$

*Prof. Naqvi is Director of the Pakistan Institute of Development Economics (P.I.D.E.). Mr. Ahmed and Mr. Khan are Research Economists at the same Institute. This study builds on a basic paper which was submitted by the senior author in the 7 th meeting of the CSCD, held at Lahore in April 1982, in response to Mr. Tarlok Singh's suggestion. The authors are deeply indebted to Professors S.I. Cohen, G. Fl $\phi$ ystad and H.C. Bos and to Drs. Fahim Khan and Nasir Khilji for their invaluable suggestions. They also acknowledge the computational help so ably provided by Mr. M. Rafiq. They are also grateful to Mr. Syed Hamid Hasan Naqavi for making stylistic improvements.

${ }^{1}$ The Pakistan Institute of Development Economics (PIDE) is actively participating in both these projects. 
Recent years have witnessed an increased interest in promoting economic co-operation among the developing countries. Such concerns have also been voiced by Pakistan, India, Bangladesh and Sri Lanka. However, these expressions of 'concern' are essentially in the form of political statements that implicitly blame some other country for not recognizing the interdependent nature of the economies of the region. Such statements, however, serve no useful purpose. A better approach to the problem of exploring possibilities, both existing and potential, of regional trade expansion and of stimulating regional economic growth is to use a regional econometric model. Such a quantitative approach has a distinct edge over purely qualitative statements, in that the former makes it possible to work out the implications of specific policies through detailed policy simulations. An example of the utility of a regional econometric model is the finding of the present study that while regional trade is small at present, there are real possibilities of increasing it through conscious policy action. The five policy simulations done for each of the four countries, the most important of which relates to changing the coefficients of regional imports, yield quantitative estimates (of dynamic multipliers) which show the extent to which increased economic collaboration benefits the countries of the region in terms of higher regional trade as well as faster growth of GNP in each of the four countries.

The plan of this study is as follows. Firstly, a 20-equation econometric model is specified in Section II for each of the four countries. These country models are then linked to each other through foreign trade equations. ${ }^{2}$ The four models specified in this study are 'simple' but not entirely 'unrepresentative'. Another approach would have been to take existing national models and link them through trade equations. However, with the exception of Pakistan and India, no other country of the region yet possesses an elaborate econometric model. It is hoped that despite its simplicity the specifications prescribed in this study would form a good starting point for a bigger regional link model. Secondly, the specified equations are estimated and the estimation results are reported in Section III. Thirdly, the 'reliability' and forecasting ability of the estimated equations are checked by historical simulations (validation) and sensitivity analysis. The results of these exercises are reported in Section IV. Fourthly, five simulations for each country - but only four for Bangladesh - have been performed in Section $V$ to explore the possibilities of expanding regional trade by various policies. This, in a way, is the most interesting part of the study.

It has been a very difficult exercise to follow this tortuous econometric route, which so far has been the 'road not taken' by the researchers in this area. In this

${ }^{2}$ Note that the Project LINK, based in the University of Pennsylvania, also links national models by means of trade flows. However, it may be noted that, unlike the practice of Project Link, we don't use 'trade share matrix' to effect the linkage. Details regarding the 'trade share matrix' approach and alternative methods of generating 'trade share matrix' are well documented in Sawyer [14] and Klein, Pauly and Voisin [7]: sense, the present study makes an original contribution to the subject, even though it must be admitted that this is still the first step. Further work will have to be done, involving generation of more reliable and comparable data, to get more robust results.

\section{SPECIFICATION OF THE REGIONAL MODEL}

In this section, a set of four highly aggregated models has been specified. For expositional purposes, each of these models is divided into six sectors, viz. private consumption expenditures, public consumption expenditures, investment, money demand, prices, and foreign trade. Each country model consists of 8 equations, out of which 5 are behavioural and 3 are definitional relations and identities. Then, through 12 trade equations for each country, the four models taken together form a mini-link system of equations. Of these trade equations, 4 are behavioural equations, while the rest are definitional relations. It should be noted that because of the nonavailability of comparable data on input supplies, no production functions have been specified. As a result, the models presented in Table 1 appear to be predominantly demand-oriented, even though supply orientation is not entirely absent from them. ${ }^{3}$

Equation 1 is the national income (GNP) identity, denoting 'domestic absorption'. Equation 2 is a simple Keynesian consumption function which treats private consumption expenditure $\left(C^{P}\right)$ as positively related to disposable income $\left(Y^{d}\right)$. According to equation 3 , public consumption expenditure depends positively on total public revenue $(Z)$. A more complete specification would include foreign aid as an additional explanatory variable. However, as comparable cross-country data are not available, we make do with the simpler functional relationship postulated in this study. In equation 4 , investment $(I)$ is treated as a function of real GNP $(Y)$, interest rate $(i)$, one-year lagged investment $\left(I_{-1}\right)$, and real money balances $\left(m^{d}\right)$. The rationale for including real money balances in the investment equation is that credit availability is expected to exercise a positive influence on total investment. ${ }^{4} \mathrm{We}$ expect a positive sign for the coefficients of real money balances GNP and lagged

${ }^{3}$ In the context of developing countries, it may be appropriate to have supply-oriented models in which supplies of inputs, rather than the adequacy of effective demand, are decisive in determining output. However, where trade equations are the prime movers of the linked system, demand orientation is not an entirely unreasonable representation of the concerned economies. At any rate, demand-oriented models have been specified for developing countries. See, for instance, the PIDE Model (1983) [10], Klein and van Peeterssen [6] and Ezaki [3]. Also note that, as pointed out by Malinvaud, supply constraints on output are relevant in both developing and developed countries [8].

${ }^{4} \mathrm{Fischer}$ and Mayer [4] also use real money balances as a proxy for credit rationing. 
investment, and a negative sign for the interest-rate coefficient. We specify, in equation 5, a money demand function with GNP and inflation $(P)$ as arguments (elements) of the function. Inflation is explained in equation $6 .^{5}$ Disposable income, in equation 7, is defined as GNP minus total direct taxes net of subsidies.

Equations 8 and 9 explain total imports and exports as sums of imports and exports of goods and services respectively, whereas equations 10 and 11 are simple identities showing that imports and exports of goods of each country are a sum of its intra-regional trade and its trade with the rest of the world $(R O W)$. Equations 12 to 15 , which link the four models, make imports of goods of the $i$ th country from the $j$ th country depend linearly on GNP in the $i$ th country. Equations 16 to 19 are ex post identities which state that, for example, Pakistan's imports from Bangladesh are the exports of Bangladesh to Pakistan etc. Equation 20 defines the trade gap.

\section{RESULTS OF ESTIMATION}

This section reports the equations estimated for the models described in Section II on the basis of data for twenty years, from 1959-60 to 1978-79, for all the four countries. ${ }^{6,7}$ Within the severe data limitations, the equations, with few exceptions, provide a satisfactory 'fit'.

\section{Private Consumption}

Estimates of private consumption expenditure for the four countries are reported in the equations below:

$$
\begin{aligned}
& \text { P.2 } \ln C_{P}^{p}=0.17+0.97 \ln Y_{P}^{d} \\
& \bar{R}^{2}=0.99 \\
& \text { D.W. }=2.00 \quad F=2553.54
\end{aligned}
$$

${ }^{5}$ While identical specifications are reported in Table 1 to explain inflation, limitations of data do not permit a uniform treatment of this equation across the four countries. For instance, in Section III, in the case of Pakistan, inflation is estimated as determined by real GNP, money supply and the import-to-GNP ratio. For Sri Lanka, inflation is related to real GNP and a oneyear lagged money supply. For Bangladesh, it is determined by real GNP, the import-to-GNP ratio and the lagged value of inflation. For India, inflation is estimated in terms of the lagged values of inflation alone.

${ }^{6}$ The instrumental variable variant of the Two-Stage Least-Squares (2SLS) estimation method has been used to get estimates of parameters. Also, to make corrections for serial correlation that many of the estimated equations suffered from, the Cochrane-Orcutt technique was used.

${ }^{7}$ The data for Bangladesh are for calendar years and are taken from $[2 ; 12 ; 15$ and 16$]$. Note that what was inter-regional trade between Bangladesh (then East Pakistan) and Pakistan (then West Pakistan) up to 1971 has been treated in this study as international trade to construct a 20-year time-series for purposes of estimation. 


\section{PAKISTAN}

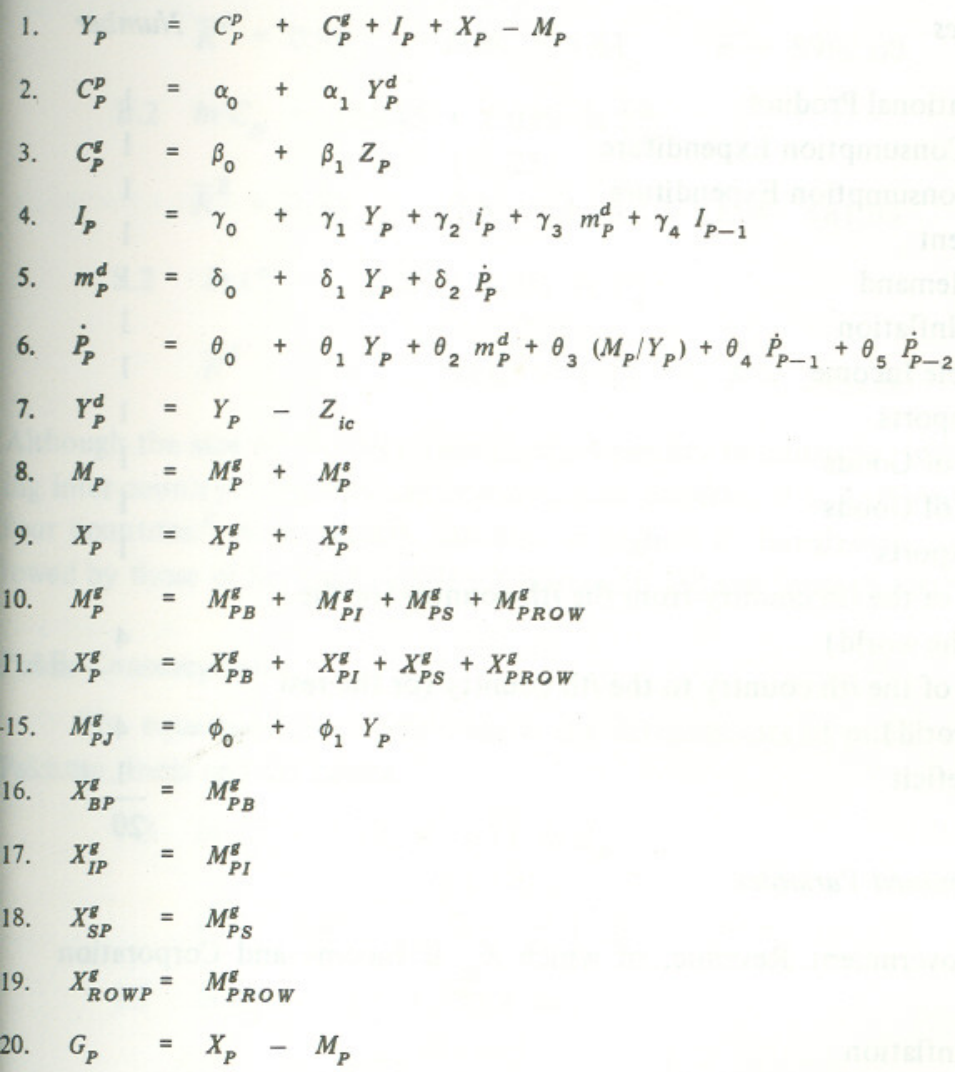

\section{INDIA}

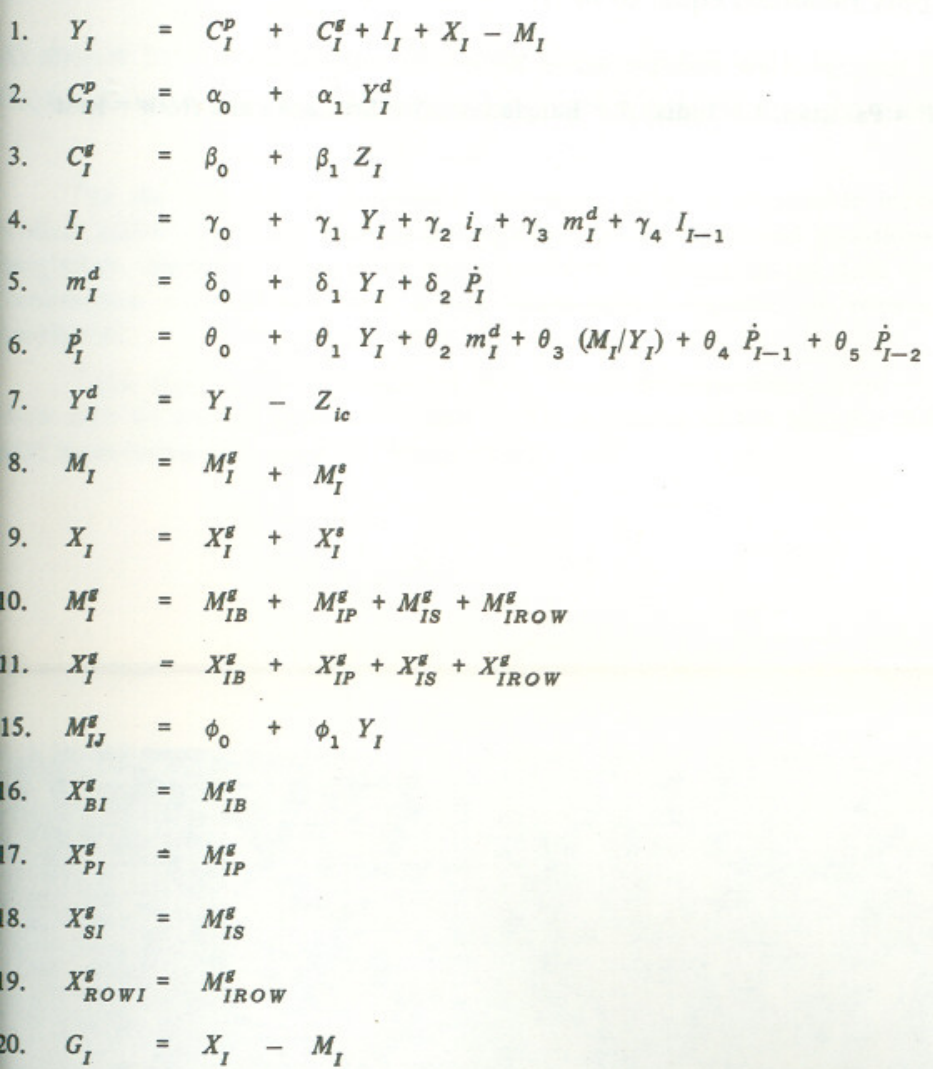

\section{BANGLADESH}

$$
\begin{aligned}
& \text { 1. } Y_{B}=C_{B}^{p}+C_{B}^{g}+I_{B}+X_{B}-M_{B} \\
& \text { 2. } C_{P}^{p}=\alpha_{0}+\alpha_{1} Y_{B}^{d} \\
& \text { 3. } C_{B}^{z}=\beta_{0}+\beta_{1} Z_{B} \\
& \text { 4. } I_{B}=\gamma_{0}+\gamma_{1} Y_{B}+\gamma_{2} i_{B}+\gamma_{3} m_{B}^{d}+\gamma_{4} I_{B-1} \\
& \text { 5. } m_{B}^{d}=\delta_{0}+\delta_{1} Y_{B}+\delta_{2} \dot{P}_{B} \\
& \text { 6. } \dot{P}_{B}=\theta_{0}+\theta_{1} Y_{B}+\theta_{2} m_{B}^{d}+\theta_{3}\left(M_{B} / Y_{B}\right)+\theta_{4} \dot{P}_{B-1}+\theta_{5} \dot{P}_{B-2} \\
& \text { 7. } Y_{B}^{d}=Y_{B}-Z_{i c} \\
& \text { 8. } M_{B}=M_{B}^{g}+M_{B}^{s} \\
& \text { 9. } X_{B}=X_{B}^{g}+X_{B}^{s} \\
& \text { 10. } M_{B}^{g}=M_{B P}^{g}+M_{B I}^{g}+M_{B S}^{g}+M_{B R O W}^{g} \\
& \text { 11. } X_{B}^{g}=X_{B P}^{g}+X_{B I}^{g}+X_{B S}^{g}+X_{B R O W}^{g} \\
& \text { 12-15. } M_{B J}^{g}=\phi_{0}+\phi_{1} Y_{B} \\
& \text { 16. } X_{P B}^{g}=M_{B P}^{g} \\
& \text { 17. } X_{I B}^{g}=M_{B I}^{g} \\
& \text { 18. } X_{S B}^{g}=M_{B S}^{g} \\
& \text { 19. } X_{R O W B}^{g}=M_{B R O W}^{g} \\
& \text { 20. } G_{B}=X_{B}-M_{B}
\end{aligned}
$$

\section{SRI LANKA}

$$
\begin{aligned}
\text { 1. } Y_{S} & =C_{S}^{p}+C_{S}^{g}+I_{S}+X_{S}-M_{S} \\
\text { 2. } C_{S}^{p} & =\alpha_{0}+\alpha_{1} Y_{S}^{d} \\
\text { 3. } C_{S}^{g} & =\beta_{0}+\beta_{1} Z_{S} \\
\text { 4. } I_{S} & =\gamma_{0}+\gamma_{1} Y_{S}+\gamma_{2} i_{S}+\gamma_{3} m_{S}^{d}+\gamma_{4} I_{S-1} \\
\text { 5. } m_{S}^{d} & =\delta_{0}+\delta_{1} Y_{S}+\delta_{2} \dot{P}_{S} \\
\text { 6. } \dot{P}_{S} & =\theta_{0}+\theta_{1} Y_{S}+\theta_{2} m_{S}^{d}+\theta_{3}\left(M_{S} / Y_{S}\right)+\theta_{4} \dot{P}_{S-1}+\theta_{5} \dot{P}_{S-2} \\
\text { 7. } Y_{S}^{d} & =Y_{S}-Z_{i c} \\
\text { 8. } M_{S} & =M_{S}^{g}+M_{S}^{g} \\
\text { 9. } X_{S} & =X_{S}^{g}+X_{S}^{g} \\
\text { 10. } M_{S}^{g} & =M_{S B}^{g}+M_{S P}^{g}+M_{S I}^{g}+M_{S R O W}^{g} \\
\text { 11. } X_{S}^{g} & =X_{S B}^{g}+X_{S P}^{g}+X_{S I}^{g}+X_{S R O W}^{g} \\
\text { 12-15. } M_{S S}^{g} & =0+\phi_{1} Y_{S} \\
\text { 16. } X_{B S}^{g} & =M_{S B}^{g} \\
\text { 17. } X_{P S}^{g} & =M_{S P}^{g} \\
\text { 18. } X_{I S}^{g} & =M_{S I}^{g} \\
\text { 19. } X_{R O W S}^{g} & X_{S R O W}^{g} \\
\text { 20. } G_{S} & =X_{S}-M_{S} \\
& X_{S}
\end{aligned}
$$




\section{LIST OF VARIABLES}

$Y=$ Gross National Product

$C^{p} \quad=$ Private Consumption Expenditure

$C^{g} \quad=$ Public Consumption Expenditure

$=$ Investment

$=$ Money demand

$=$ Rate of Inflation

$=$ Disposable Income

$=$ Total Imports

$=$ Imports of Goods

$=$ Exports of Goods

$=$ Total Exports

$=$ Imports of the $i$ th country from the $j$ th country (or the rest of the world)

$=$ Exports of the $i$ th country to the $j$ th country (or the rest of the world)

$=$ Trade deficit

Exogenous/Predetermined Variables

$Z \quad=$ Total Government Revenue, of which $Z_{i c}$ is Income and Corporation taxes

$=$ Lagged Inflation

$=$ Lagged Investment

$=$ Imports of Services

$=$ Exports of Services

$=$ Exports of the $j$ th country to the rest of the world

$=$ Money Supply (assumed equal to $\mathrm{m}^{d}$ )

Note: $\quad$ The subscript $P=$ Pakistan, $I=$ India, $B=$ Bangladesh, $S=$ Sri Lanka and $R O W=$ Rest of the World.

$$
\begin{gathered}
1.2 \quad \ln C_{I}^{p}=3.18+0.73 \ln Y_{I}^{d} \\
\bar{R}^{2}=0.99 \quad(7.39)
\end{gathered}
$$$$
2 \ln C_{B}=-0.445+1.039 \ln Y_{B}^{d}
$$$$
\bar{R}^{2}=0.97(25.25)
$$$$
\bar{R}^{2}=0.97 \quad \text { D.W. }=1.95 \quad F=581.99
$$$$
\mathrm{S} .2 \ln C_{S}^{p}=-0.58+1.03 \ln Y_{S}^{d}
$$$$
\bar{R}^{2} \quad(29.21)
$$

$$
\bar{R}^{2}=0.99 \quad \text { D.W. }=1.93 \quad F=2482.00
$$

Although the size of the mpc (marginal propensity to consume) is different, suggesting inter-country differences in consumption patterns, it is uniformly high in all the four countries. ${ }^{8}$ As expected, the mpc is highest in Bangladesh (0.97) and is followed by those of Sri Lanka (0.76), Pakistan (0.75) and India (0.68). ${ }^{9}$

\section{Public Consumption}

The equations given below show the determinants of public consumption for Pakistan, India and Sri Lanka.

$$
\begin{aligned}
& \text { P.3 } \ln C_{P}^{g}=2.13+0.71 \ln Z_{P} \\
& \bar{R}^{2}=0.89 \quad \text { D. W. }=1.89 \quad F=162.00 \\
& \text { I.3 } \ln C_{I}^{g}=1.18+0.88 \ln Z_{I} \\
& \bar{R}^{2}=0.99 \quad(11.83) \\
& \bar{R}^{2}=0.99 \quad \text { D.W. }=1.30 \quad F=5982.00 \\
& \text { S.3 } \ln C_{S}^{g}=3.02+0.53 \ln Z_{S} \\
& \bar{R}^{2}=0.91 \quad \text { D.W. }=1.70 \quad F=185.85
\end{aligned}
$$

As shown by the elasticities of public consumption with respect to public revenue, there are inter-country differences in public expenditure patterns. The equations

${ }^{8}$ In the absence of consistent time-series data on disposable income, gross domestic product (GDP) has been used as an argument in the estimated equations for Sri Lanka and Bangladesh. Similarly, because of non-availability of disaggregated data on private and public consumption expenditures, only a total-consumption-expenditure equation is estimated for Bangladesh.

${ }^{9}$ The mpc estimates computed from the coefficients (elasticities) of the estimated equations refer to average values of $C$ and $Y$. The estimates of the mpc for Pakistan are consisten with those obtained in the PIDE Model (1983) [10]. 
show that the elasticity of public consumption with respect to public revenue is highest for India (0.88), which is followed by those for Pakistan (0.71) and Sri Lanka (0.53).

\section{Investment Expenditure}

Estimates of investment expenditure for all the four countries are reported in the equations below:

$$
\begin{aligned}
& \text { P.4 } \ln I_{P}=-12.02+2.17 \ln Y_{P}-1.12 \ln i_{P} \\
& \begin{array}{lll}
\bar{R}^{2}=0.98 & (3.15) & (2.04) \\
& \text { D.W. }=1.79 & F=416.5
\end{array} \\
& \text { I.4 } \ln I_{I}=-8.15+1.53 \ln Y_{I}-0.02 \ln i_{I} \\
& \bar{R}^{2}=0.99 \quad \text { D.W. }=1.77 \quad F=792.00 \\
& \text { B.4 } \ln I_{B}=-35.72+\underset{(4.52)}{4.59} \ln Y_{B}-\underset{(4.16)}{1.39} \ln i_{B} \\
& \begin{array}{lll}
\bar{R}^{2}=0.70 & \text { D.W. }=1.74 & F=22.98
\end{array} \\
& \mathrm{~S} .4 \ln I_{S}=-2.23+0.65 \ln I_{S-1}+0.48 \ln Y_{S}+0.045 \ln m_{S}^{d} \\
& \begin{array}{lll}
\bar{R}^{2}=0.90 & \text { D. } W .=1.77 & (1.17) \\
& F=56.20
\end{array}
\end{aligned}
$$

GNP and interest rate have been used as explanatory variables for Pakistan, India and Bangladesh. It can be seen that GNP turns out to be the most significant variable explaining the behaviour of investment in the four countries. Interest rate is not significant for India (Eq. I.4), but is significant for Pakistan and Bangladesh (Eqs. P.4 and B.4). It may be noted that the estimated equation for Sri Lanka (Eq. S.4) features lagged investment and real balances as explanatory variables. ${ }^{10}$ Though real balances are not statistically significant, the positive sign of the coefficient shows that availability of credit has led to an increase in investment in Sri Lanka. Lagged investment is significant, and bears the correct sign. However, as opposed to the other equations, the equation for Sri Lanka shows that the GNP coefficient is insignificant for that country.

\section{Demand for Money}

The equations stated below report estimates of money-demand function for the four countries.

$$
\begin{aligned}
& \text { P.5 } \ln m_{P}^{d}=-14.85+2.50 \ln Y_{P}+0.83 \ln \dot{P}_{P}-1.02 \ln i_{P} \\
& \text { (5.72) (1.18) (2.86) } \\
& \bar{R}^{2}=0.94 \quad \text { D.W. }=1.96 \quad F=95.00 \\
& \text { I.5 } \ln m_{I}^{d}=-12.99+1.96 \ln Y_{I}+0.71 \ln \dot{P}_{I} \\
& \begin{array}{lll}
\bar{R}^{2}=0.99 & \text { D.W. }=1.43 & F=792.00
\end{array} \\
& \text { B.5 } \ln m_{B}^{d}=-5.12+1.36 \ln Y_{B}+0.28 \ln \dot{P}_{B} \\
& \begin{array}{lll}
\bar{R}^{2}=0.95 & \text { D. } W .=1.49 & (0.69) \\
& & F=152.00
\end{array} \\
& \text { S.5 } \ln m_{S}^{d}=-4.13+\underset{(7.88)}{0.99} \ln Y_{S}+\underset{(2.06)}{4.02 \ln \dot{P}_{S}} \\
& \bar{R}^{2}=0.98 \quad \text { D.W. }=1.78 \quad F=372.95
\end{aligned}
$$

Note that GNP and the expected rate of inflation are explanatory variables in all the equations, and that changes in GNP have been the most important determinants of money demand in these countries. The elasticity of demand for money differs considerably across the countries, but is uniformly high. ${ }^{11}$ It is greater than unity for Pakistan, India and Bangladesh and nearly unity for Sri Lanka. Such high elasticity values imply that there is considerable 'room' for non-inflationary monetary expansion in these countries, particularly in Pakistan, India and Bangladesh. Another interesting variable used to explain changes in the demand for money is the expected rate of inflation. However, this variable turned out to be insignificant for Pakistan and Bangladesh. For Pakistan, the interest-rate variable is significant, with the correct sign.

\section{Inflation}

Equations P.6 to S.6 explain the phenomenon of inflation for India, Pakistan, Sri Lanka and Bangladesh.

$$
\begin{aligned}
& \text { P.6 } \ln \dot{P}_{P}=-0.46-0.005 \ln Y_{P}+0.38 \ln m_{P}^{d}-0.26 \ln \left(M_{P} / Y_{P}\right) \\
& \begin{array}{lll}
\bar{R}^{2}=0.43 & (0.08) & (1.18) \\
& \text { D.W. }=1.86 & F=5.27
\end{array} \\
& \text { I.6 } \ln \dot{P}_{I}=0.06+\underset{(2.73)}{0.79} \ln P_{I-1}-0.62 \ln P_{I-2} \\
& \bar{R}^{2}=0.31 \quad \text { D.W. }=2.39 \quad \begin{array}{l}
(2.54) \\
F=4.67
\end{array}
\end{aligned}
$$

${ }^{10}$ This is because the (positive) sign of the interest-rate variable was incorrect.
${ }^{11}$ See Khan [5]. 


$$
\begin{aligned}
& \text { B.6 } \ln \dot{P}_{B}=10.01-0.94 \ln Y_{B}+0.37 \ln \left(M_{B} / Y_{B}\right)+0.1 \ln \dot{P}_{B-1} \\
& \begin{array}{lll}
\bar{R}^{2}=0.46 & \text { D.W. }=1.89 \quad(3.31) \\
F=5.94
\end{array} \\
& \text { S.6 } \ln \dot{P}_{S}=0.53-\underset{(2.03)}{0.066} \ln Y_{S}+0.102 \ln m_{S-1}^{d} \\
& \bar{R}^{2}=0.95 \quad \text { D.W. }=1.91 \quad F=166.29
\end{aligned}
$$

For Pakistan, GNP, money supply and import-to-GNP ratio have been used as arguments of the equation. Here the money-supply coefficient is positive. The import-GNP ratio, used as an explanatory variable to account for the effect of imported inflation, is significant, with a negative sign. This suggests that inflation in Pakistan is not necessarily an imported phenomenon. Indeed, the negative sign of the coefficient of this variable suggests that greater imports have had a dampening effect on inflation! However, the coefficient of GNP is very small and insignificant. ${ }^{12}$

For want of comparable data, a different specification has been estimated for Sri Lanka. GNP and lagged money supply are explanatory variables here. The coefficient of lagged money supply is significant, with a positive sign. It may be noted that the GNP coefficient is significant for Sri Lanka and Bangladesh. The negative sign of this variable is correct, suggesting that an increase in GNP has tended to dampen inflation in both these countries. It is interesting that, unlike that for Pakistan, the coefficient of import-to-GNP ratio for Bangladesh is positive and significant. The non-availability of consistent data did not permit estimation of a more meaningful equation for India.

\section{Foreign Trade}

The estimated foreign-trade equations, which link the four economies, are set out below:

\section{A. Pakistan}

$$
\begin{aligned}
\text { P.12 } \quad M_{P B}=27.08+0.019 & Y_{P}-0.019 \quad Y_{P}(D) \\
& (5.08) \quad(0.57) \\
\bar{R}^{2}= & 0.96 \quad \text { D.W. }=2.01 \quad F=274.83
\end{aligned}
$$

${ }^{12}$ For a fuller explanation of this 'hypothesis', see the PIDE Model (1983) [10]. Note that equation P.6, which features the rate of change in the price level, is somewhat different from the one used in the PIDE Model (1983), where price level is the dependent variable. As a result, the various coefficients in the two equations differ in size, even though they convey the same message.

$$
\begin{aligned}
& \text { P.13 } \ln M_{P I}=-1.18+0.57 \ln Y_{P}-0.74 \ln Y_{P}(D) \\
& \begin{array}{lll}
\bar{R}^{2}=0.76 & \text { D. } W .=1.86 & F=30.14
\end{array}
\end{aligned}
$$

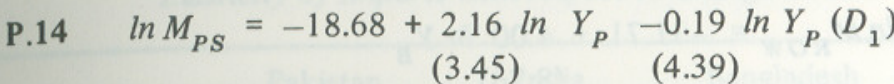

$$
\begin{aligned}
& +0.08 \ln Y_{P}\left(D_{2}\right) \\
& \text { (1.58) } \\
& \bar{R}^{2}=0.90 \quad \text { D.W. }=2.01 \quad F=53.93 \\
& \text { P.15 } \ln M_{\text {ROW }}=-2.41+1.01 \ln Y_{P}-0.006 \ln Y_{P}(D) \\
& \bar{R}^{2}=0.72 \quad D W .=1.85 \quad F=25.50
\end{aligned}
$$

B. India

$$
\begin{aligned}
& \text { I.12 } \ln M_{I P}=-3.89+0.60 \ln Y_{I}-0.48 \ln Y_{I}(D) \\
& \bar{R}^{2}=0.96 \quad(0.88) \quad(16.99) \\
& \bar{R}^{2}=0.96 \quad \text { D.W. }=1.62 \quad F=204.00 \\
& \text { I.13 } \ln M_{I S}=32.32-2.39 \ln Y_{I} \\
& \bar{R}^{2}=0.14 \quad \text { D.W. }=1.88 \quad F=4.22 \\
& \text { I.14 } M_{I B}=119.93-0.0002 Y_{I}-0.0002 Y_{I}(D) \\
& \bar{R}^{2}=0.43 \quad \text { D.W. }=2.03 \quad \text { F } \quad(1.02)=8.17 \\
& \text { I.15 } \ln M_{\text {ROW }}=0.22+0.75 \ln Y_{I}
\end{aligned}
$$

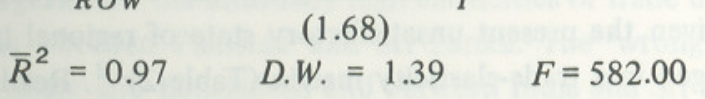

\section{Bangladesh}

$$
\begin{array}{lll}
\text { B.12 } & M_{B P}=83.24+0.003 Y_{B}-0.007 Y_{B}(D) \\
& \bar{R}^{2}=0.63 \quad(0.47) \quad \text { D.W. }=1.89 \quad F=17.26 \\
\text { B.13 } & M_{B I}=185.116+0.005 Y_{B}-0.019 Y_{B}(D) \\
& \bar{R}^{2}=0.33 \quad \text { D.W. }=2.37 \quad(2.49) \\
& & F=5.67
\end{array}
$$


B.14

$$
\begin{array}{ccc}
\ln M_{B S}=2.13+0.11 \ln Y_{B}-0.078 \cdot \ln Y_{B}(D) \\
\bar{R}^{2}=0.72 \quad & (0.22) & (2.17) \\
& \text { D.W. }=1.87 & F=25.5
\end{array}
$$

B.15

$$
\begin{aligned}
& \ln M_{R O W}=-31.71+\underset{ }{4} \begin{array}{l}
4.00 \ln Y_{B} \\
(8.76)
\end{array} \\
& \bar{R}^{2}=0.80 \quad \text { D.W. }=1.70 \quad F=76.74
\end{aligned}
$$

\section{Sri Lanka}

$$
\begin{aligned}
& \text { S.12 } \ln M_{S P}=-16.38+2.23 \ln Y_{S} \\
& \bar{R}^{2}=0.80 \quad \text { D.W. }=2.05 \quad F=78.40 \\
& \text { S.13 } \ln M_{S I}=-5.71+1.19 \ln Y_{S} \\
& \bar{R}^{2}=0.59 \quad \text { D. } W .=1.65 \quad F=28.54 \\
& \text { S.14 } \ln M_{S B}=-17.89+2.13 \ln Y_{S} \\
& \bar{R}^{2}=0.33 \quad \text { D.W. }=1.48 \quad F=10.55 \\
& \text { S.15 } \ln M_{R O W}=-0.68+0.89 \ln Y_{S} \\
& \bar{R}^{2}=0.79 \quad \text { D. } W .=1.63 \quad F=71.06
\end{aligned}
$$

Since the primary purpose of the paper is to examine the scope of trade expan sion between Pakistan, India, Sri Lanka and Bangladesh, these equations are of great importance. To facilitate a better understanding of what these equations tell about such possibilities, given the present unsatisfactory state of regional trade, the trade elasticities are arranged in a trade-elasticity matrix (Table 2$)^{13}$. Read vertically, the matrix shows the effect of a one-percent increase in GNP in the $i$ th country on imports from the $j$ th country. If read horizontally, the rows of the matrix indicate the effect of a one-percent increase in GNP in the $i$ th country on export from the $j$ th country.

${ }^{13}$ For equations regressed in the linear form, the elasticity estimates were calculated for consistency. Secondly, dummy variables represented by $Y(D)$ were used to capture the effects of 'abnormal' events.
Table 2

Trade-Elasticity Matrix:

Elasticity of Imports with respect to Change in GNP

\begin{tabular}{lcccc}
\hline & Pakistan & India & Bangladesh & Sri Lanka \\
\hline Pakistan & - & 0.60 & 0.48 & 2.23 \\
India & 0.57 & - & 0.53 & 1.19 \\
Bangladesh & 2.05 & $-0.72^{*}$ & - & 2.13 \\
Sri Lanka & 2.16 & $-2.39 *$ & 0.11 & - \\
\hline Rest of the World & 1.01 & 0.75 & 4.00 & 0.89 \\
\hline Source: $\quad \begin{array}{l}\text { Equations P. 12 }- \text { S. 15. } \\
\text { *May indicate wrong sign. }\end{array}$ & & &
\end{tabular}

The interpretation of these results is subject to four important reservations. Firstly, there are severe (data) problems in estimating India's trade with Bangladesh and Sri Lanka. Secondly, trade between India and Pakistan remained suspended for several consecutive years. Hence, minimum values were assumed to fill in the "blank year'. Thirdly, international trade between Pakistan and Bangladesh was really interregional trade before 1971. Fourthly, trade between Pakistan and Sri Lanka increased suddenly after 1971, when Pakistan's imports of tea from Bangladesh (the former East Pakistan) virtually came to an end. The third and fourth reservations explain to a large extent the unusually high elasticities of trade between Pakistan and Bangladesh and between Pakistan and Sri Lanka. The 'wrong' elasticity signs for trade between India and Bangladesh and between India and Sri Lanka may be attributed to data deficiency. However, an economic explanation is also possible: Indian imports from Sri Lanka have increased inelastically over time, which has made Sri Lanka import less from India to maintain a bilateral trade balance.

However, subject to these important reservations, the following points should be noted. Firstly, both Pakistan and India - the latter more than the former - have generally followed import-substitution policies. Thus, for instance, the elasticity of trade between India and the rest of the world is less than unity. Secondly, Bangladesh, followed by Pakistan, is the most 'outward looking' country in the region. Thirdly, while Bangladesh and India appear to discriminate somewhat against the region, Pakistan and Sri Lanka do not seem to do so. It follows from this analysis 
that the odds are as much against as they are for regional trade expansion. If anything, one should hope for the best as far as the responsiveness of regional trade to favourable 'expansionist' policies is concerned. This issue is examined in detail in Section V,

\section{VALIDATION AND SENSITIVITY ANALYSIS OF THE MODEL}

\section{A. Validating National Models}

In the preceding sections, an attempt has been made to simulate the four national economies through a set of fairly homogeneous country models which are then linked through a set of trade equations. Considering the somewhat 'stylized' nature of the country models, the estimated equations, taken individually, 'explain' rather well the behaviour of the basic dependent variables. However, the explanatory power of the entire model is best established by the fact that,through 'historical' simulation or validation of the model, it also 'tracks' the actual data fairly accurately, i.e. the values predicted by the model are close to the actual values observed during the sample period.

In this section, such an exercise has been done to test the predictive power of the model. Although there are a number of criteria used to judge the forecasting accuracy of the model, we use the Theil Inequality Coefficient (TIC) statistic in this paper. ${ }^{14}$ In addition to this criterion, simulation graphs have also been plotted for all the important variables to show how closely the model predicts the various turning points of the actual data. (To save space, these graphs are not reported in the text.)

A cursory look at Table 3, which gives TIC values, shows that on the whole the estimated equations predict 'economic reality' fairly accurately. The estimated results of the link model, as a whole, are not too bad: for approximately one-half of the total number of variables included in the model, the margin of error measured by the TIC is within 5 percent or less than 5 percent. For the rest of the variables, it is 10 percent or higher. The details of validation for Pakistani, Indian, Bangladeshi and Sri Lankan models are set out below.

\section{Pakistan}

For GNP, private and public consumption, total consumption and inflation. the TIC statistic in each case indicates a good fit: it lies between 2 percent and 5 percent, while in the cases of Pakistan's imports from ROW and total imports of

${ }^{14}$ The value of TIC $=\mu$ lies between zero and one. If $\mu=0$, there is a perfect fit, and if $\mu=1$, the predictive performance of the model is nil. For further details, see Pindyck and Rubinfeld [13, pp. $360-67]$.
Table 3

Validation Results of Pakistan, India, Bangladesh and Sri Lanka Models

\begin{tabular}{|c|c|c|c|c|}
\hline \multirow{2}{*}{$\begin{array}{l}\text { Endogenous } \\
\text { Variables }\end{array}$} & \multicolumn{4}{|c|}{ Theil Inequality Coefficient (TIC) for } \\
\hline & Pakistan & India & Bangladesh & Sri Lanka \\
\hline \multicolumn{5}{|l|}{ All Countries of the Region } \\
\hline Gross National Product & 0.05 & 0.02 & 0.021 & 0.037 \\
\hline Private Consumption & 0.05 & 0.02 & - & 0.022 \\
\hline Public Consumption & 0.05 & 0.03 & - & 0.03 \\
\hline Total Consumption & 0.05 & 0.02 & 0.016 & 0.02 \\
\hline Total Investment & 0.12 & 0.03 & 0.160 & 0.16 \\
\hline Rate of Inflation & 0.02 & 0.03 & 0.10 & 0.009 \\
\hline Demand for Money & 0.13 & 0.05 & 0.086 & 0.044 \\
\hline \multicolumn{5}{|l|}{ Pakistan } \\
\hline Imports of Pakistan from Sri Lanka & 0.17 & - & - & - \\
\hline Imports of Pakistan from India & 0.28 & - & - & - \\
\hline Imports of Pakistan from Bangladesh & 0.11 & - & - & - \\
\hline Imports of Pakistan from ROW & 0.10 & - & - & - \\
\hline Total Imports of Pakistan & 0.09 & - & - & - \\
\hline \multicolumn{5}{|l|}{ India } \\
\hline Imports of India from Pakistan & - & 0.25 & - & - \\
\hline Imports of India from Sri Lanka & - & 0.43 & - & - \\
\hline Imports of India from Bangladesh & - & 0.32 & - & - \\
\hline Imports of India from ROW & - & 0.10 & - & - \\
\hline Total Imports of India & - & 0.10 & - & - \\
\hline \multicolumn{5}{|l|}{ Bangladesh } \\
\hline Imports of Bangladesh from Pakistan & - & - & 0.21 & - \\
\hline Imports of Bangladesh from India & - & - & 0.30 & - \\
\hline Imports of Bangladesh from Sri Lanka & - & - & 0.11 & - \\
\hline Imports of Bangladesh from ROW & - & - & 0.07 & - \\
\hline Total Imports of Bangladesh & - & - & 0.075 & - \\
\hline \multicolumn{5}{|l|}{ Sri Lanka } \\
\hline Imports of Sri Lanka from Pakistan & - & - & - & 0.10 \\
\hline Imports of Sri Lanka from India & - & - & - & 0.22 \\
\hline Imports of Sri Lanka from Bangladesh & - & - & - & 0.37 \\
\hline Imports of Sri Lanka from ROW & - & - & - & 0.15 \\
\hline Total Imports of Sri Lanka & - & - & - & 0.14 \\
\hline
\end{tabular}


Pakistan, this statistic stands around 10 percent. The simulation graphs (not reproduced) show that for GNP, private and public consumption, total consumption and demand for money, the actual and predicted values are extremely close to each other. Regarding endogenous variables relating to foreign trade, the TIC values lie between 9 percent and 28 percent. Overall, the simulated series of all endogenous variables 'track' the historical data fairly well. It may also be noted that the fit is also good in the sense that it predicts the turning points in the historical data with a fair degree of accuracy. Particularly in the case of Pakistan's imports from Sri Lanka, the actual and predicted series show two distinct clusters, one of which symbolizes the fact that Pakistan's imports from Sri Lanka rose sharply in 1972. ${ }^{15}$ Pakistan's imports from India remained at extremely low levels from 1966-67 to 1974-75 and its imports from Bangladesh remained disrupted for three years, from 1970-71 to 1972-73.

India

The values of TIC for all the endogenous variables in the Indian model are reported in Table 3. It is interesting to note that the Indian model also has a high predictive power. The actual and predicted series are exceedingly close to each other as indicated by very low values of the TIC for most of the endogenous variables (in country model). Out of twelve variables, nine have an error margin of less than 10 percent. Even more important, the simulated values of the endogenous variables capture all the turning points in the actual data. However, with the exception of the equations for Indian imports from 'the rest of the world' and 'total imports of India', the three trade equations of the Indian model provide a rather poor fit. The TIC for these equations is relatively high, ranging from 25 percent to 43 percent. More work is required on these equations.

\section{Bangladesh}

The actual and predicted series of all the endogenous variables are very close to each other, in spite of the sharp fluctuations in the actual data series due to many abnormal events. The TIC statistic for each of the endogenous variables, except those for imports of Bangladesh from India $\left(M_{B I}\right)$ and from Pakistan $\left(M_{B P}\right)$, lies below 20 percent. Overall, the predicted series of all endogenous variables track the historical data well and capture almost all the turning points.

${ }^{15}$ As mentioned earlier, the bulk of Pakistan's tea, which until the end of 1971 came from East Pakistan, was imported from Sri Lanka from 1972 onwards. As a result, a sharp jump is recorded in the imports of Pakistan from Sri Lanka in 1972.
Sri Lanka

The TIC statistic for each of the endogenous variables, except that of total investment, indicates that the margin of error lies below 4 percent. Endogenous variables relating to the foreign-trade model show an error margin of 10-37 percent. The predicted series duplicate the actual series with a high degree of precision for the country model. Most of the turning points have also been captured very well. As regards the trade equations, some of the simulated series overpredict in some years while they underpredict in other years. Considering the fact that the regional trade had been fluctuating owing to political and other reasons, the performance of the trade equations is not quite bad.

\section{B. Sensitivity Analysis of the Model}

The sensitivity of the 'Link Model' has been checked by giving two types of shocks to the models. ${ }^{16}$ These shocks consist of changes in

(i) the values of the exogenous variables, and

(ii) the values of the estimated coefficients.

In the first experiment, exports of a particular country to the rest of the world were increased by 10 percent and the TIC values were calculated. Table 4 reports the results of the experiment. For Pakistan, India and Bangladesh, the maximum difference between before- and after-shock TIC values ( $\triangle$ TIC) is one percent or even less than that, while for Sri Lanka the maxinum difference is 4 percent.

In the second experiment, the import coefficient was changed by 10 percent for all the countries. The results, again reported in Table 4 , show that the error margin in all the countries for all the variables is less than one percent. The results of this exercise show that the equations of the model are dynamically stable in that the equations of the model converge after being subjected to various exogenous shocks.

\section{POLICY SIMULATIONS}

The analysis presented so far shows that the regional LINK MODEL represents a fairly reliable simulation of the 'reality on the ground'. After successful validation and sensitivity tests, the next important step is to see the extent to which this 'reality' can be modified, if not drastically changed. The estimated values of dynamic multipliers are used to forecast the effects of alternative economic policies on the

${ }^{16}$ A powerful criterion to test the overall performance of the model and its stability is to determine the 'sensitivity' of the model - to test how relatively insensitive the model is to small exogenous shocks. A model is unstable if even a small (percentage) change in 'estimated coefficients' or in 'exogenous variables' produces large cyclical fluctuations. The TIC values calculated after the shock are subtracted from the TIC values obtained from the validation exercise to get the values of $\triangle \mathrm{TIC}$. 
Sensitivity Analysis Results for Pakistan, India, Bangladesh and Sri Lanka Models

\begin{tabular}{|c|c|c|c|c|c|c|c|c|}
\hline $\begin{array}{l}\text { Endogenous } \\
\text { Variables }\end{array}$ & \multicolumn{2}{|c|}{ Pakistan } & \multicolumn{2}{|c|}{ India } & \multicolumn{2}{|c|}{ Bangladesh } & \multicolumn{2}{|c|}{ Sri Lanka } \\
\hline \multicolumn{9}{|l|}{ All Countries of the Region } \\
\hline $\begin{array}{l}\text { Gross National Product } \\
\text { Private Consumption } \\
\text { Public Consumption } \\
\text { Total Consumption } \\
\text { Total Investment } \\
\text { Demand for Money } \\
\text { Rate of Inflation }\end{array}$ & $\begin{array}{l}-0.00103 \\
0.0 \\
0.0 \\
0.0 \\
-0.01020 \\
-0.01100 \\
0.0\end{array}$ & $\begin{array}{l}-0.00069 \\
0.0 \\
0.0 \\
0.0 \\
-0.00150 \\
-0.00270 \\
-0.00114\end{array}$ & $\begin{array}{l}-0.00004 \\
0.0 \\
0.0 \\
0.02107 \\
-0.00123 \\
-0.00428 \\
0.0\end{array}$ & $\begin{array}{l}-0.00003 \\
0.0 \\
0.0 \\
-0.00777 \\
0.0 \\
-0.00011 \\
0.0\end{array}$ & $\begin{array}{l}0.00306 \\
- \\
- \\
0.0 \\
-0.01190 \\
0.0 \\
0.00030\end{array}$ & $\begin{array}{c}0.00005 \\
- \\
- \\
0.0 \\
0.0 \\
-0.00002 \\
0.00020\end{array}$ & $\begin{array}{l}-0.00239 \\
0.0 \\
0.0 \\
0.0 \\
-0.00760 \\
-0.00739 \\
0.00013\end{array}$ & $\begin{array}{l}-0.00053 \\
0.0 \\
0.0 \\
0.0 \\
-0.00240 \\
-0.00071 \\
-0.00003\end{array}$ \\
\hline \multicolumn{9}{|l|}{ Pakistan } \\
\hline $\begin{array}{l}\text { Imports of Pakistan from Sri Lanka } \\
\text { Imports of Pakistan from India } \\
\text { Imports of Pakistan from Bangladesh } \\
\text { Imports of Pakistan from ROW } \\
\text { Total Imports of Pakistan }\end{array}$ & $\begin{array}{l}-0.00140 \\
-0.00450 \\
-0.00390 \\
-0.00062 \\
-0.00144\end{array}$ & $\begin{array}{l}-0.00190 \\
- \\
-0.00050 \\
-0.00053 \\
-0.00177\end{array}$ & $\begin{array}{l}- \\
- \\
- \\
-\end{array}$ & $\begin{array}{l}- \\
- \\
- \\
-\end{array}$ & $\begin{array}{l}- \\
- \\
- \\
-\end{array}$ & $\begin{array}{l}- \\
- \\
- \\
-\end{array}$ & $\begin{array}{l}- \\
- \\
- \\
-\end{array}$ & $\begin{array}{l}- \\
- \\
- \\
-\end{array}$ \\
\hline \multicolumn{9}{|l|}{ India } \\
\hline $\begin{array}{l}\text { Imports of India from Pakistan } \\
\text { Imports of India from Sri Lanka } \\
\text { Imports of India from Bangladesh } \\
\text { Imports of India from ROW } \\
\text { Total Imports of India }\end{array}$ & $\begin{array}{l}- \\
- \\
- \\
-\end{array}$ & $\begin{array}{l}- \\
- \\
- \\
-\end{array}$ & $\begin{array}{r}0.00060 \\
-0.00330 \\
-0.00010 \\
0.00057 \\
0.00057\end{array}$ & $\begin{array}{l}- \\
-0.00010 \\
0.0 \\
-0.00003 \\
-0.00042\end{array}$ & $\begin{array}{l}- \\
- \\
- \\
-\end{array}$ & $\begin{array}{l}- \\
- \\
- \\
-\end{array}$ & $\begin{array}{l}- \\
- \\
- \\
-\end{array}$ & $\begin{array}{l}- \\
- \\
- \\
-\end{array}$ \\
\hline
\end{tabular}

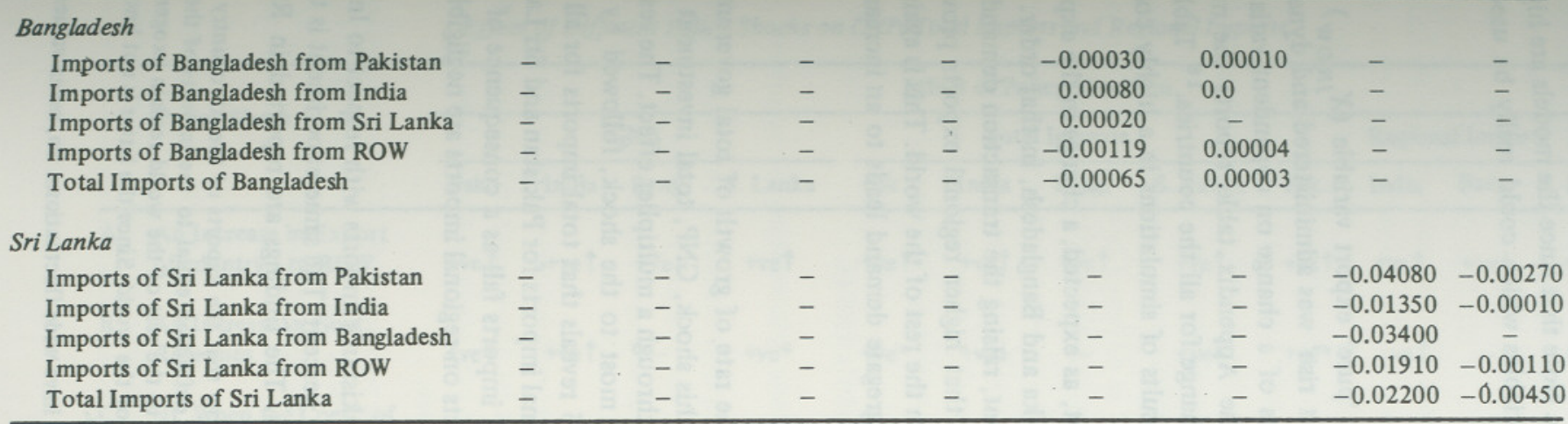

Note: $\triangle \mathrm{TIC}_{1}$ is the difference of TIC before \& after the shock, the shock being a 10-percent increase in exports of a particular country to ROW. $\triangle \mathrm{TIC}_{2}$ is the difference of TIC before \& after the shock, the shock being a 10-percent increase in the import coefficients. 
GNPs of the region and on inter-regional trade. Note that since the models are highly aggregated, there are only few exogenous variables which could really be used as policy variables for simulation purposes.

\section{A. Changing Exports}

After deducting intra-regional trade, a 'pure' export variable $\left(X_{j R O W}\right)$ was calculated. ${ }^{17} \mathrm{~A}$ policy shock of a '10-percent rise' was administered and dynamic multipliers were computed to find the effects of a change on dependent variables for six years, from 1979-80 to $1984-85$. The Appendix table reports the mean values of the multipliers obtained after this change for all the countries. ${ }^{18}$ Table 5 , based on the Appendix table, sets out the results of simulations in a highly convenient form.

A glance at Table 5 (Row A) shows that, as expected, a change in the exports increases the GNPs of India, Pakistan, Sri Lanka and Bangladesh, in that order. The induced rise in GNP increases total investment, raising the transaction demand for money in the process. The table also shows that higher regional exports provoke greater imports from the region as well as from the rest of the world. This is again an expected result, because an increase in the aggregate demand leads to an increase in the demand for imports.

\section{B. Changes in Total Government Revenues}

In this experiment (Row B, Table 5), the rate of growth of total government revenues is set at 10 percent. As a result of this shock, GNP, total investment and demand for money of every country increase through a multiplier effect. The results show that the Indian economy responds the most to the shock, followed by the economies of Pakistan and Sri Lanka. Table 5 reveals that total imports for all the countries increase but at different rates. Regional imports for Pakistan and Sri Lanka have a positive effect whereas India's regional imports fall as a consequence of this shock. However, the positive and negative effects on regional imports are negligible.

\section{Changes in Import Coefficients}

In this experiment, the coefficients of Pakistan's imports with respect to India, Bangladesh and Sri Lanka are increased by 10 percent. The same experiment is then repeated for India, Bangladesh and Sri Lanka. The findings are reported in Rows

${ }^{17}$ Equations 16 to 19 , given in Section II, show that the exports of the $j$ th country and of the rest of the world to the $i$ th country are by definition equal to the imports of the $i$ th country from them. The exports of the $j$ th country to the rest of the world remain exogenous because these are a function of the GNP of the rest of the world. Since the latter is not known, because these are a function of the GNP of the rest of
the former acts as an exogenous variable in the system.

${ }^{18}$ The actual dynamic multiplier values do not have wide fluctuations. So, mean values are not affected by extreme values. 
C(i) to C(iv) of Table 5. It is clear that out of twelve cases (for all the four countries with three experiments each), the GNP decreases in ten cases. For the remaining two cases - India's imports from Bangladesh and Sri Lanka - the GNP goes up. ${ }^{19}$ Similarly, total investment and demand for money are lowered for these ten cases. Table 5 shows that a rise in the import coefficient of each of the four countries produces a positive effect on total imports. However, this effect will decrease over time for India and Bangladesh, increase for Sri Lanka, and oscillate for Pakistan. The effect on regional trade is positive and it has an increasing trend for all except two cases. It shows that, over time, regional trade will increase between Pakistan, Bangladesh and Sri Lanka but India's imports from Bangladesh and Sri Lanka will decrease.

The effects of these policy experiments are also clear from Figures 1 and $2 .^{20}$ An inspection of these graphs readily shows that the first and second experiments (higher exports and higher government revenue) have an expansionary effect in all the countries, but the intensity of the 'reaction' is different in every case. For the third and fourth experiments (higher coefficients for Pakistan's imports from India and Bangladesh), the effects on the GNP are higher or lower depending on the import behaviour of the particular trading partner. The results of these policy experiments show that there is no need for any undue pessimism regarding the possibility of regional trade expansion if appropriate expansionary regional policies are pursued.

\section{CONCLUDING OBSERVATIONS}

The 'facts' about the state of regional economic collaboration are as follows:

(i) If the import behaviour of India was correctly estimated, then Indian trade in the region is mainly inward-looking. On balance, it turns more to extraregional than to intra-regional sources of supply to satisfy its demand for imports. The same holds for exports.

(ii) Pakistan will turn, as it did in the past, to regional sources of supply, particularly to Sri Lanka and India, to meet its import demand. However, this result may not hold as the reasons for high trade elasticities (see Section III) may not remain relevant in the future.

(iii) Bangladesh is the least oriented towards regional trade. The responsiveness of its imports from extra-regional sources rises much higher than the responsiveness of its imports from intra-regional sources when there is a change in GNP.

${ }^{19}$ This may have been due to the less reliable estimates of equations I.13 and I.14.

${ }^{20}$ Though the effect of these shocks is considered for every country, we have, to save space, reproduced only two graphs. The simulation graphs for other countries follow a similar

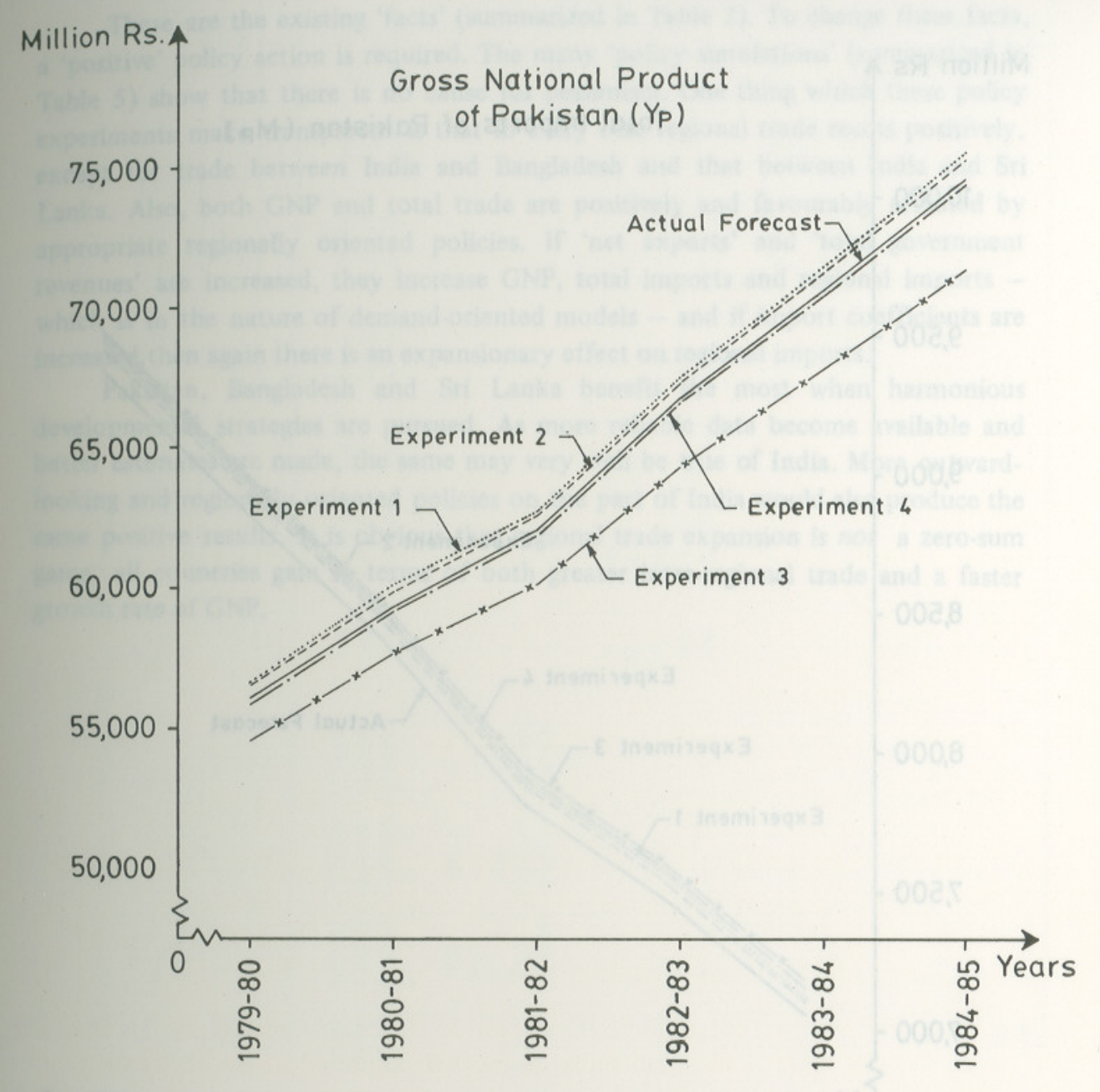

Figure 1

Experiment 1 . When $\mathrm{Z}$ was increased by 10 percent.

Experiment 2. When $\mathrm{X}_{\mathrm{PROW}}$ was increased by 10 percent.

Experiment 3. When the coefficient of Pakistan's imports from India was increased by 10 percent.

Experiment 4. When the coefficient of Pakistan's imports from Bangladesh was increased by 10 percent. 


\section{Million Rs.}

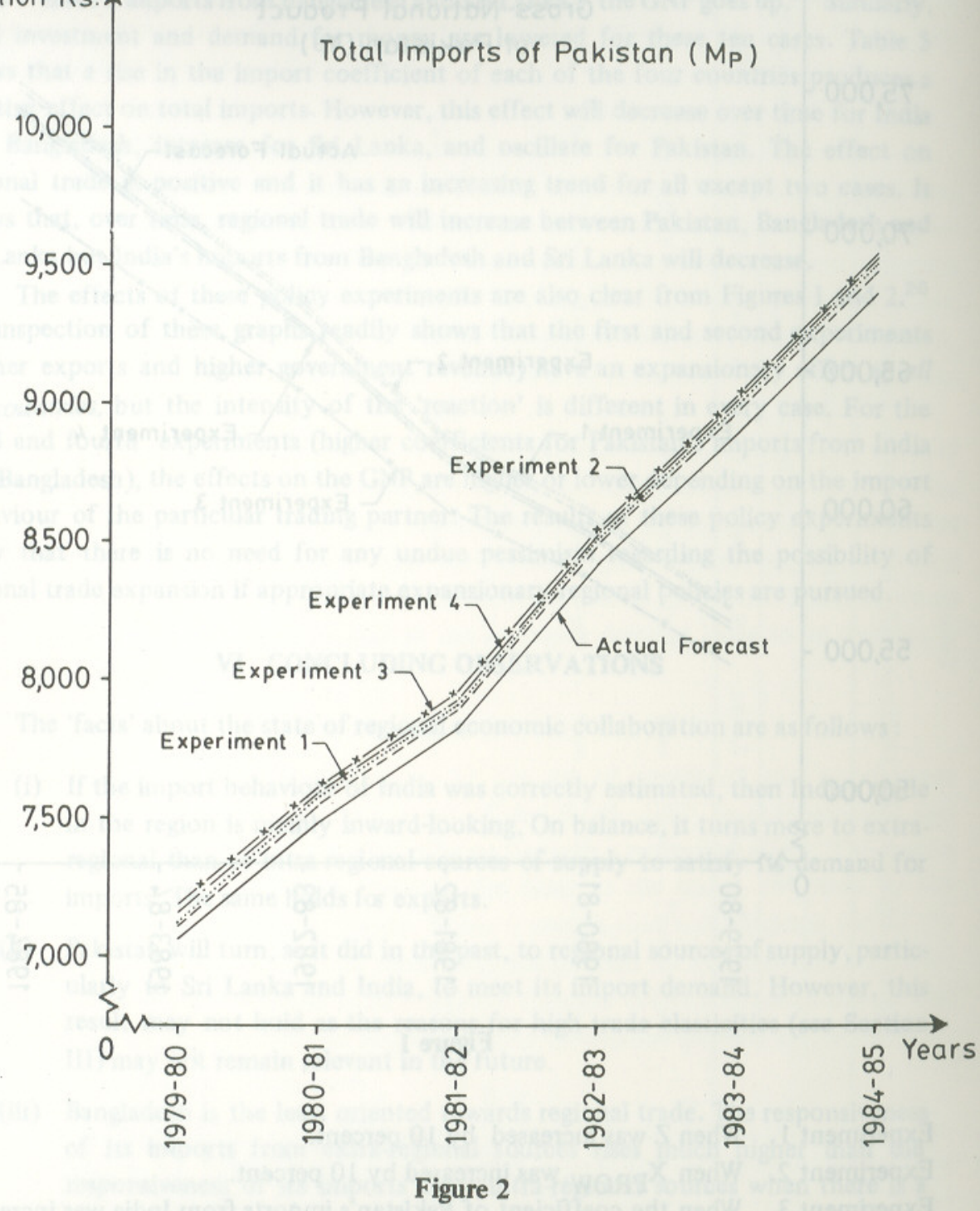

Experiment 1 . When $\mathrm{Z}$ was increased by 10 percent.

Experiment 2. When $\mathrm{X}_{\mathrm{PROW}}$ was increased by 10 percent.

Experiment 3. When the coefficient of Pakistan's imports from India was increased by 10 percent.

Experiment 4. When the coefficient of Pakistan's imports from Bangladesh was increased by 10 percent.
These are the existing 'facts' (summarized in Table 2). To change these facts, a 'positive' policy action is required. The many 'policy simulations' (summarized in Table 5) show that there is no cause for pessimism. One thing which these policy experiments make transparent is that in every case regional trade reacts positively, except for trade between India and Bangladesh and that between India and $\mathrm{Sr}$ Lanka. Also, both GNP and total trade are positively and favourably affected by appropriate regionally oriented policies. If 'net exports' and 'total government revenues' are increased, they increase GNP, total imports and regional imports which is in the nature of demand-oriented models - and if import coefficients are increased,then again there is an expansionary effect on regional imports.

Pakistan, Bangladesh and Sri Lanka benefit the most when harmonious developmental strategies are pursued. As more reliable data become available and better estimates are made, the same may very well be true of India. More outwardlooking and regionally-oriented policies on the part of India would also produce the same positive results. It is obvious that regional trade expansion is not a zero-sum game: all countries gain in terms of both greater intra-regional trade and a faster growth rate of GNP. 


\section{REFERENCES}

1. Agarwala, R. An Econometric Model of India, 1948-61. London: Frank Cass. 1970.

2. Alamgir, M., and Lodewijk J.J.B. Berlage. Bangladesh National Income and Expenditure: 1949-50 to 1969-70. Dacca: The Bangladesh Institute of Development Studies. 1974.

3. Ezaki, M. "Linking National Econometric Models of Japan, USA and the East and Southeast Asian Countries - A Pilot Study". Southeast Asian Studies. Vol. 17, No. 2. September 1979.

4. Fischer, B., and Thomas Mayer. "The Impact of Rising International Interest Rates on Developing Countries: The South Korean Experience". Kiel Institute of World Economics, Department IV, August 1982.

5. Khan, Ashfaque H. "Permanent Income, Inflation Expectations and the Money Demand Function in Developing Countries". Pakistan Development Review. Vol. XXI, No. 4. Winter 1982.

6. Klein, L.R., and A. Van Peeterssen. "Forecasting World Trade Within Project Link". In R.J. Bal (ed.), The International Linkage of National Economic Models. Amsterdam: North-Holland. 1973.

7. Klein, L.R., Peter Pauly and Pascal Voisin. "The World Economy - A Global Model". Perspectives. Vol. 2, No. 2. May 1982.

8. Malinvaud, E. "Econometrics Faced with the Need of Macro-Economic Policy". Econometrica. November 1981.

9. Naqvi, Syed Nawab Haider, and Khwaja Sarmad. Pakistan's Economy through the Seventies. Islamabad: Pakistan Institute of Development Economics. March 1984. (Esp. Ch.2)

10. Naqvi, Syed Nawab Haider, Ashfaque H. Khan, Nasir M. Khilji, Ather Maqsood Ahmed and Associates: The P.I.D.E. Marco-econometric Model of Pakistan's Economy. Vol. 1. Islamabad: Pakistan Institute of Development Economics. 1983.

11. Naqvi, Syed Nawab Haider, and Ashfaque H. Khan. "A Link Model for Pakistan, India, Bangladesh and Sri Lanka". Islamabad: Pakistan Institute of Development Economics. December 1982. (Research Report No. 138)

12. Pakistan. Central Statistical Office. Foreign Trade Statistics of Pakistan. Karachi. (Various issues)

13. Pindyck, R.S., and D.L. Rubinfeld. Econometric Models and Economic Forecasts (2nd ed.). Tokyo: McGraw-Hill Inc. 1981.

14. Sawyer, John A. (ed.) Modelling the International Transmission Mechanism. Amsterdam: North-Holland. 1979.

15. United Nations. Direction of Trade. Washington, D.C.: International Monetary Fund. (Various issues)

16. World Bank. World Tables, Baltimore, N.J.: The Johns Hopkins University Press. (Various issues) 